unbiased bioinformatics approach can yield useful therapeutic targets to enhance nerve regeneration (8). However, the current data on both ATF3 (21) and Hsp27 (8) show only modest improvements in the rate of axonal regeneration in short-term, short-distance nerve regeneration. Therefore, translation into a clinically useful target awaits confirmation in models of long-distance nerve repair in large animals. One thing that would be extremely interesting to investigate is whether overexpression of both ATF3 and Hsp27 in the same animal has an additive or synergistic effect in enhancing the rate of peripheral nerve regeneration. The group led by Clifford Woolf is at the forefront of this research and has the mice needed to examine this issue at hand. Combining their prior work with ATF3 (21) and current work on Hsp27 (8) should be a logical next step. Once a proof-of-concept demonstration with overexpression of both ATF3 and Hsp27 is shown to be a feasible solution, drug-screening assays for small molecules that may mimic their activities may lead to actual improvements in peripheral nerve regeneration.

\section{Acknowledgments}

Ahmet Höke's research is supported by NINDS, The Foundation for Peripheral Neuropathy, Merkin Family Foundation, and Adelson Medical Research Foundation.
Address correspondence to: Ahmet Höke, Johns Hopkins School of Medicine, 855 N. Wolfe Street, Rangos 248, Baltimore, Maryland 21205, USA. Phone: 410.955.2227; Fax: 410.502.5459; E-mail: ahoke@jhmi.edu.

1. Noble J, Munro CA, Prasad VS, Midha R. Analysis of upper and lower extremity peripheral nerve injuries in a population of patients with multiple injuries. J Trauma. 1998;45(1):116-122.

2. Sunderland S. Factors influencing the course of regeneration and quality of recovery after nerve suture. Brain. 1952;75(1):19-54.

3. Woodhall B, Beebe GW. Peripheral Nerve Regeneration: A Follow-up Study Of 3,656 World War II Injuries. Washington, DC, USA: US Government Printing Office; 1956.

4. Dvali L, Mackinnon S. The role of microsurgery in nerve repair and nerve grafting. Hand Clin. 2007; 23(1):73-81.

5. Brushart T. Nerve Repair. New York, New York, USA: Oxford University Press; 2011.

6. Grafstein B. Role of slow axonal transport in nerve regeneration. Acta Neuropathol. 1971; 5(suppl 5):144-152.

7. Hoffman PN, Lasek RJ. Axonal transport of the cytoskeleton in regenerating motor neurons: constancy and change. Brain Res. 1980;202(2):317-333.

8. Ma CHE, et al. Accelerating axonal growth promotes motor recovery after peripheral nerve injury in mice. J Clin Invest. 2011;121(11):4332-4347.

9. Fu SY, Gordon T. Contributing factors to poor functional recovery after delayed nerve repair: prolonged axotomy. J Neurosci. 1995;15(5 pt 2):3876-3885.

10. Fu SY, Gordon T. Contributing factors to poor functional recovery after delayed nerve repair: prolonged denervation. J Neurosci. 1995;15(5 pt 2):3886-3895.

11. Hoke A. Mechanisms of disease: what factors limit the success of peripheral nerve regeneration in humans? Nat Clin Pract Neurol. 2006;2(8):448-454.
12. Terenghi G, Calder JS, Birch R, Hall SM. A morphological study of Schwann cells and axonal regeneration in chronically transected human peripheral nerves. J Hand Surg Br. 1998;23(5):583-587.

13. Weinberg HJ, Spencer PS. The fate of Schwann cells isolated from axonal contact. J Neurocytol. 1978; 7(5):555-569.

14. Hoke A, Gordon T, Zochodne DW, Sulaiman OA. A decline in glial cell-line-derived neurotrophic factor expression is associated with impaired regeneration after long-term Schwann cell denervation. Exp Neurol. 2002;173(1):77-85.

15. Li H, Terenghi G, Hall SM. Effects of delayed reinnervation on the expression of c-erbB receptors by chronically denervated rat Schwann cells in vivo. Glia. 1997;20(4):333-347.

16. Heine W, Conant K, Griffin JW, Hoke A. Transplanted neural stem cells promote axonal regeneration through chronically denervated peripheral nerves. Exp Neurol. 2004;189(2):231-240.

17. Zuo J, Hernandez YJ, Muir D. Chondroitin sulfate proteoglycan with neurite-inhibiting activity is upregulated following peripheral nerve injury. $\mathrm{J} \mathrm{Neu}$ robiol. 1998;34(1):41-54.

18. Gordon T, Tyreman N, Raji MA. The basis for diminished functional recovery after delayed peripheral nerve repair. J Neurosci. 2011;31(14):5325-5334.

19. McQuarrie IG, Grafstein B, Gershon MD. Axonal regeneration in the rat sciatic nerve: effect of a conditioning lesion and of dbcAMP. Brain Res. 1977;132(3):443-453.

20. Tsujino $\mathrm{H}$, et al. Activating transcription factor 3 (ATF3) induction by axotomy in sensory and motoneurons: A novel neuronal marker of nerve injury. Mol Cell Neurosci. 2000;15(2):170-182.

21. Seijffers R, Mills CD, Woolf CJ. ATF3 increases the intrinsic growth state of DRG neurons to enhance peripheral nerve regeneration. J Neurosci. 2007;27(30):7911-7920.

22. Varejao AS, Melo-Pinto P, Meek MF, Filipe VM, Bulas-Cruz J. Methods for the experimental functional assessment of rat sciatic nerve regeneration. Neurol Res. 2004;26(2):186-194.

\title{
Do MDL-1+ cells play a broad role in acute inflammation?
}

\author{
Peter A. Ward \\ University of Michigan Medical School, Department of Pathology, Ann Arbor, Michigan, USA.
}

\begin{abstract}
Dengue virus (DV) reacts with myeloid DAP12-associating lectin-1 (MDL-1) on immature polymorphonuclear leukocytes. Interaction of DV with MDL-1 ${ }^{+}$ cells triggers systemic inflammatory response syndrome (SIRS) and dengue shock syndrome (DSS), with subsequent multi-organ failure. In this issue of the JCI, Cheung et al. find that sterile acute liver injury in mice is associated with the accumulation of MDL- $1^{+}$cells and that triggering of these cells by DV or an MDL-1-specific agonist antibody leads to SIRS, shock, and death. These findings may have broad mechanistic and therapeutic implications for the development of SIRS, sepsis, and shock in humans exposed to a wide array of infectious and non-infectious conditions.
\end{abstract}

Conflict of interest: The author has declared that no conflict of interest exists.

Citation for this article: J Clin Invest. 2011; 121(11):4234-4237. doi:10.1172/JCI60122.
Localized activation of the innate immune system is critical for host defenses against invasive pathogens and for repairing tissues damaged by trauma, ischemia/reperfusion injury, or chemical-induced injury (1). In some instances, the localized response to infection or sterile tissue damage becomes progressive, escalating to systemic inflammatory response syndrome (SIRS), a condition that can progress to shock, multi-organ failure, and death (2). The production of proinflammatory cytokines and ROS by activated myeloid lineage cells, especially polymorphonuclear leukocytes (PMNs) and macrophages, is a key component of SIRS. However, the cascade of events that causes SIRS to progress to shock, defined clinically as systemic hypotension, is not well defined. Myeloid lineage cell produc- 


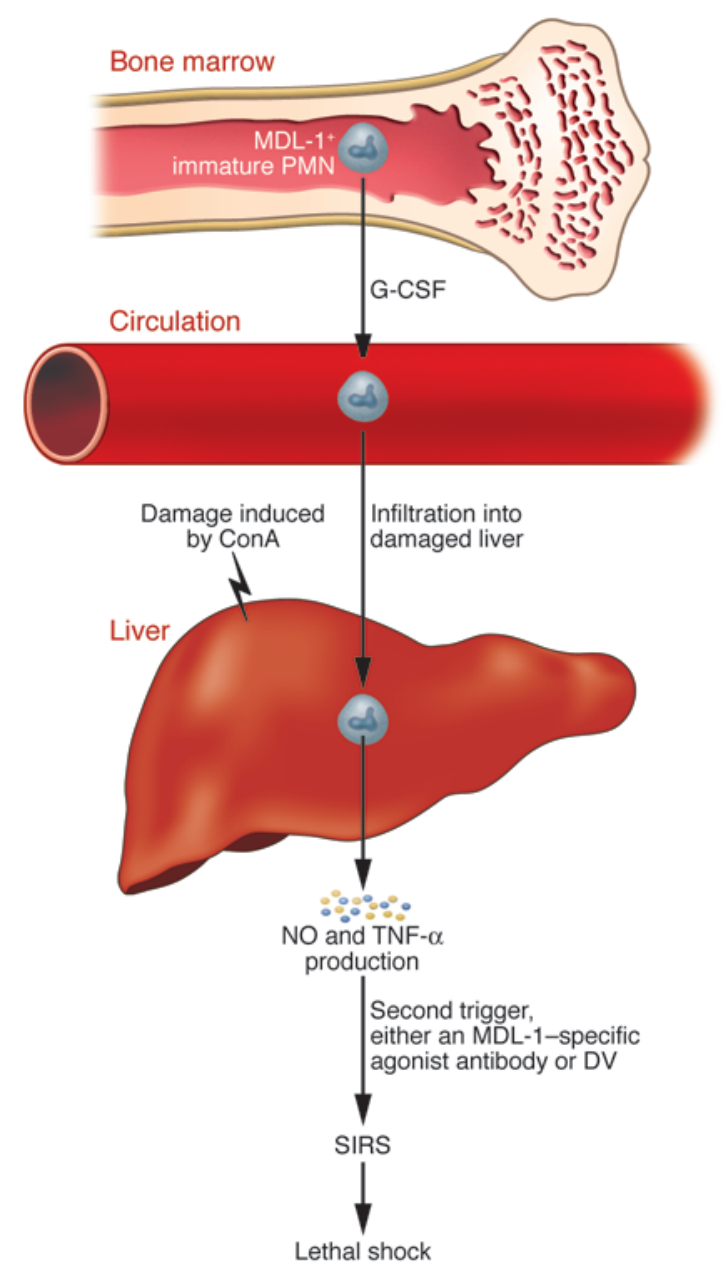

tion of TNF- $\alpha$ and NO, which mediate vascular changes that lead to capillary leakage and pathologic vasodilation, is thought to have an important role in the progression of SIRS to shock. However, roles for activation products of complement proteins and acute-phase proteins have also been identified. Further definition of the cellular and molecular mechanisms involved in the progression of SIRS to shock could provide new approaches for therapeutic intervention.

\section{Dengue shock syndrome}

One condition that could conceivably be treated with a therapeutic designed to prevent progression of SIRS to shock and lethality is dengue shock syndrome (DSS), a condition estimated to kill 20,000 people each year (3). DSS is a life-threatening condition that arises in some individuals infected with DV, a mosquito-borne virus endemic in tropical and subtropical areas of the world. There are four DV serotypes. Initial infection with any one of these usually results in mild disease, although in some cases DSS devel- ops. Secondary infection with a different DV serotype is associated with a dramatically increased susceptibility to DSS.

DV can interact with myeloid DAP12associating lectin-1 (MDL-1; also known as CLEC5A), a C-type lectin expressed by myeloid cells (4), leading to production of proinflammatory cytokines such as TNF- $\alpha$ (5). Blocking DV interaction with MDL-1 reduces vascular leakage and shock in a mouse model of DSS (5). In this issue of the JCI, Cheung and colleagues provide new insights into the characteristics of MDL- $1^{+}$myeloid cells and their function in inflammation (6). These data could lead to new approaches for treating multiple conditions characterized by the progression of SIRS to shock and not just DSS.

\section{MDL-1+ cells in sterile inflammation}

The work presented by Cheung et al. in this issue of the JCI (6) extends the role of MDL- $1^{+}$cells, which appear to be immature PMNs. The data indicate that MDL- $1^{+}$cells participate in sterile injury-induced acute

\section{Figure 1}

Proposed pathways that are MDL-1 dependent and lead to SIRS, liver injury, and lethal shock in the setting of ConA-induced acute liver injury. In this scheme, release of both PMNs and MDL-1+ cells occurs in the bone marrow, under the influence of G-CSF (6). Upon entry into the bloodstream, MDL-1+ cells and PMNs traffic into the liver, which has been injured by injection of ConA. ConA initiates inflammation that damages the liver and sets the stage for accumulation of both PMNs and $\mathrm{MDL}-1^{+}$cells. This damage is both PMNand CD4+ $\mathrm{T}$ cell-dependent (17). As Cheung et al. describe (6), MDL-1+ cells produce NO and TNF- $\alpha$, which injure the liver and also initiate SIRS and lead to multi-organ failure. This chain of events, which leads to the death of mice, can be greatly attenuated by use of neutralizing antibodies specific for MDL-1 or nitric oxide synthase, or antibodies specific for G-CSF. Also, NO scavengers greatly reduce lethality in this model (6). inflammatory responses resulting in SIRS and the subsequent development of shock and lethality. The authors used the concanavalin A (ConA) model of sterile acute liver injury and found that ConA-induced liver injury was associated with a dramatic increase in G-CSF levels in the liver and serum and that this growth factor induced release of MDL- $1^{+}$cells from the bone marrow into the blood (Figure 1). These cells trafficked to the liver, where they produced TNF- $\alpha$ and NO, triggering organ damage, SIRS, shock, and lethality. In this study (6), a second trigger (either an MDL-1-specific agonist antibody or DV) was required to cause progression to SIRS, shock, and lethality. Cheung and colleagues went on to define the signaling pathways in MDL-1 ${ }^{+}$ cells that regulate NO and TNF- $\alpha$ production, which might prove useful therapeutic targets for preventing the progression of SIRS to shock and lethality. Further, as in the mouse model of DSS (5), infusion of a blocking antibody specific for MDL-1 abolished the adverse consequences of ConA 
treatment (6), providing an additional potential therapeutic strategy for preventing the triggering of shock.

\section{Fate of hematopoietic cells exiting the bone marrow}

Cheung and colleagues show that G-CSF is critical for the release of MDL- $1^{+}$cells from the bone marrow into the blood (6). They also found that infusion of G-CSF into mice increased the number of MDL- $1^{+}$ cells accumulating in the injured liver, suggesting that G-CSF has a role in promoting cell trafficking to sites of injury. G-CSF and CXC chemokines (such as IL-8 and CXCL4) are also known to cause proliferation of PMN precursors (and perhaps MDL- $1^{+}$ cells) in the bone marrow, resulting in expanded numbers of PMNs released into the blood (7). PMNs spend only a few days in the blood stream (8) and then, by mechanisms described below, transmigrate into tissues/organs. The PMN life span is short due to the tendency of these cells in tissues to undergo apoptosis, which seems to prevent excessive buildup of PMNs in tissues, thereby limiting the extent of PMN-dependent tissue injury (9). To what extent these features of PMNs apply to MDL- $1^{+}$cells is unknown. If $\mathrm{MDL}-1^{+}$cells are also subject to apoptosis once in tissues, this could represent a way to moderate their role in proinflammatory events.

\section{Fate of leukocytes in the vascular compartment}

Much is known about PMN trafficking, and it is possible that MDL- $1^{+}$cells behave like PMNs after they are released from the bone marrow. The bloodstream serves as a highway to deliver leukocytes to tissues and organs, where they form a defensive shield against microorganisms and assist in the repair of tissue damage such as that occurring after ischemia/reperfusion or as a result of trauma. Leukocytes express various adhesion-promoting factors on their cell surfaces (e.g., $\beta_{2}$ integrins such as CD11b/CD18) that facilitate cell adhesion to the endothelium. Activated endothelial cells also express adhesion-promoting molecules (e.g., E- and P-selectin and ICAM-1) that facilitate leukocyte adhesion (10). By this duality, leukocytes ultimately transmigrate into tissues, where they enhance the local innate immune system. Under conditions of excessive PMN buildup and unregulated activation of these recruited leukocytes in tissues, cells and matrix proteins may be damaged (Figure 2).
Trauma, infection, ischemia/reperfusion, hemorrhagic shock, etc.

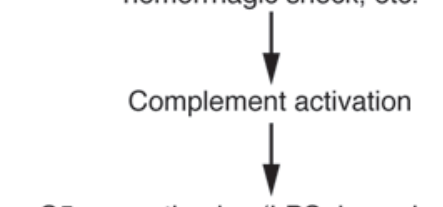

C5a \pm costimulus (LPS, hypoxia, etc.)

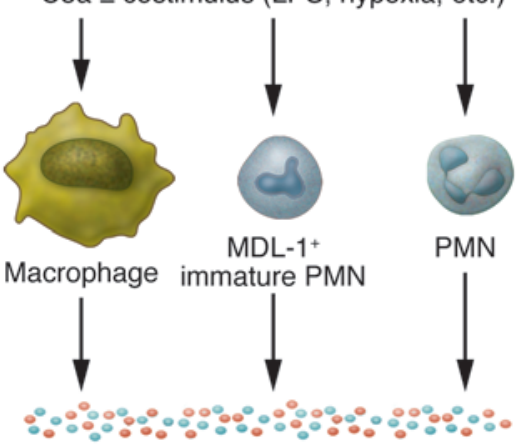

Cytokines/chemokines, oxidants, proteases

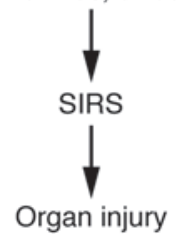

Complement, PMNs, MDL-1+ cells (?), and inflammation

The complement system is a major player in the innate immune system, causing tissue recruitment of PMNs via C5a (an 8-kDa peptide derived from complement component 5 [C5]) and its receptor, C5aR (11). It seems likely that, if MDL- $1^{+}$cells express $\mathrm{C} 5 \mathrm{aR}$, they will be similarly responsive to C5a. The C5a/C5aR axis is usually protective, allowing PMN recruitment to sites of bacterial infection and to damaged/destroyed tissue, as in myocardial ischemia (12). The recruited PMNs and macrophages will remove bacteria and tissue debris. Protective effects of C5a occur as long as its levels are carefully regulated, leading to enhanced innate immune responses (phagocytosis, chemotaxis, ROS production) in macrophages and PMNs. Another example of C5a's protective effects relates to containment of bacteria during experimental pneumonia, which requires availability of C5aR, presumably on PMNs (13). The excessive C5a production that occurs in experimental sepsis (cecal perforation) and accompanying engagement of C5aR (14) result in dysregulated MAPK signaling pathways (15) and loss of resistance to gut-derived bacteria, which become blood-borne (16). In the cecal perforation model, innate immune functions

\section{Figure 2}

Role of C5a in events leading to SIRS and organ injury in a variety of conditions. A common feature of these conditions associated with organ injury is complement activation, which leads to generation of the powerful anaphylatoxin $\mathrm{C} 5 \mathrm{a}$. $\mathrm{C} 5 \mathrm{a}$ is highly proinflammatory and interacts with its receptors $(\mathrm{C} 5 \mathrm{aR}$ and C5L2) on macrophages and PMNs, resulting in activation of innate immune responses such as phagocytosis, chemotaxis, and formation of ROS and reactive nitrogen species (RNS). When a co-stimulus such as LPS is present, the phagocyte responses are magnified. Via production and release of cytokines/chemokines, oxidants (ROS, RNS), and proteases, SIRS often develops and is frequently associated with multi-organ failure. It seems likely that, being immature PMNs, MDL-1+ cells may follow PMNs that accumulate in organs/ tissues under conditions described above.

(chemotaxis, phagocytosis) of PMNs were compromised. It is likely that the same innate immune functions in MDL- $1^{+}$cells would also be impaired during sepsis.

\section{Work to be done}

Cheung et al. (6) are to be commended for their work, which sets the stage for a much broader series of studies to define the roles of MDL- $1^{+}$cells in infectious and noninfectious disorders. Important questions include: (a) What are the natural noninfectious ligands for MDL-1? (b) What is the evidence that MDL- $1^{+}$cells participate in the protective effects of innate immunity? (c) Do MDL- $1^{+}$cells express C5aR and respond to $\mathrm{C} 5 \mathrm{a}$ in ways similar to PMNs? (d) Is the recruitment pathway of MDL- $1^{+}$ cells to tissues similar to the recruitment of PMNs? (e) In general, do MDL- $1^{+}$cells accumulate in tissues in parallel to PMNs in acute inflammatory responses?

\section{Acknowledgments}

The studies were supported in part by NIH grants GM-29507 and GM-61656. The excellent secretarial support of Beverly Schumann and Sue Scott is gratefully acknowledged.

Address correspondence to: Peter A. Ward, University of Michigan Medical School, 
Department of Pathology, 1301 Catherine Road, 7520 MSRB I, Ann Arbor, MI 481095602, USA. Phone: 734.647.2921; Fax: 734.764.4308; E-mail: pward@umich.edu.

1. Pluddemann A, Mukhopadhyay S, Gordon S. Innate immunity to intracellular pathogens: macrophage receptors and responses to microbial entry. Immunol Rev. 2011;240(1):11-24.

2. Gustot T. Multiple organ failure in sepsis: prognosis and role of systemic inflammatory response. Curr Opin Crit Care. 2011;17(2):153-159.

3. Green S, Rothman A. Immunopathological mechanisms in dengue and dengue hemorrhagic fever. Curr Opin Infect Dis. 2006;19(5):429-436.

4. Bakker AB, Baker E, Sutherland GR, Phillips JH, Lanier LL. Myeloid DAP12-associating lectin (MDL)-1 is a cell surface receptor involved in the activation of myeloid cells. Proc Natl Acad Sci US A.
1999;96(17):9792-9796.

5. Chen ST, et al. CLEC5A is critical for dengue-virus-induced lethal disease. Nature. 2008; 453(7195):672-676.

6. Cheung R, et al. Activation of MDL-1 (CLEC5A) on immature myeloid cells triggers lethal shock in mice. J Clin Invest. 2011;121(11):4446-4461.

7. Eash KJ, Means JM, White DW, Link DC. CXCR4 is a key regulator of neutrophil release from the bone marrow under basal and stress granulopoiesis conditions. Blood. 2009;113(19):4711-4719.

8. Pillay J, et al. In vivo labeling with $2 \mathrm{H} 2 \mathrm{O}$ reveals a human neutrophil lifespan of 5.4 days. Blood. 2010; 116(4):625-627.

9. Simon HU. Neutrophil apoptosis pathways and their modifications in inflammation. Immunol Rev. 2003;193:101-110.

10. Ley K, Laudanna C, Cybulsky MI, Nourshargh S. Getting to the site of inflammation: the leukocyte adhesion cascade updated. Nat Rev Immunol. 2007; 7(9):678-689.
11. Lee H, Whitfeld PL, Mackay CR. Receptors for complement C5a. The importance of C5aR and the enigmatic role of C5L2. Immunol Cell Biol. 2008; 86(2):153-160.

12. Zhang H, Qin G, Liang G, Li J, Barrington RA, Liu DX. C5aR-mediated myocardial ischemia/reperfusion injury. Biochem Biophys Res Commun. 2007; 357(2):446-452

13. Hopken UE, Lu B, Gerard NP, Gerard C. The C5a chemoattractant receptor mediates mucosal defence to infection. Nature. 1996;383(6595):86-89.

14. Rittirsch D, et al. Functional roles for C5a receptors in sepsis. Nat Med. 2008;14(5):551-557.

15. Huber-Lang $M$, et al. Role of C5a in multiorgan failure during sepsis. JImmunol. 2001;166(2):1193-1199.

16. Ward PA. The harmful role of C5a on innate immunity in sepsis. J Innate Immun. 2010;2(5):439-445.

17. Bonder CS, Ajuebor MN, Zbytnuik LD, Kubes P, Swain MG. Essential role for neutrophil recruitment to the liver in concanavalin A-induced hepatitis. J Immunol. 2004;172(1):45-53.

\title{
The long and the short of aberrant ciliogenesis in Huntington disease
}

\author{
Jeh-Ping Liu and Scott O. Zeitlin
}

Department of Neuroscience, University of Virginia, Charlottesville, Virginia, USA.

\begin{abstract}
Huntington disease (HD) is a dominantly inherited neurodegenerative disorder that is caused by a mutant huntingtin $(H T T)$ gene encoding a version of the $\mathrm{Htt}$ protein with an expanded polyglutamine stretch. Although the HTT gene was discovered more than 18 years ago, the functions of normal $\mathrm{Htt}$ and the mechanisms by which mutant $\mathrm{Htt}$ causes disease are not well defined. In this issue of the JCI, Keryer et al. uncovered a novel function for normal $\mathrm{Htt}$ in ciliogenesis and report that mutant $\mathrm{Htt}$ causes hypermorphic ciliogenesis and ciliary dysfunction. These observations suggest that it is now critical to understand the extent to which ciliary dysfunction contributes to the different symptoms of HD and to determine whether therapeutic strategies designed to normalize ciliary function can ameliorate the disease.
\end{abstract}

Huntington disease (HD) is an autosomaldominant disorder caused by expansion of a CAG repeat in the first exon of the huntingtin (HTT) gene (1). This repeat encodes an expanded stretch of polyglutamine residues at the amino terminus of the $\mathrm{Htt}$ protein. HD is predominantly an adultonset disorder that is characterized by progressive neuronal cell death primarily in the striatum and deep layers of the cortex. Clinically, it is characterized by motor, cognitive, and neuropsychiatric abnormalities that cause a progressive loss of functional capacity and reduced life span (2). There are currently no effective treatments for

Conflict of interest: The authors have declared that no conflict of interest exists.

Citation for this article: J Clin Invest. 2011; 121(11):4237-4241. doi:10.1172/JCI60243. this devastating neurodegenerative disease. This stems largely from an incomplete understanding of the cellular and molecular mechanisms by which mutant Htt causes disease.

Evidence obtained from cell culture and animal model studies supports the hypothesis that the polyglutamine expansion in mutant Htt confers on the protein both a toxic gain of function and a partial loss of normal function (3). More than 100 Htt-interacting proteins have been identified, implicating $\mathrm{Htt}$ as a participant in a diverse array of cellular processes (4). One of the most predominant of these processes is microtubule-based transport of vesicles and organelles. The role of Htt in intracellular transport is mediated by its direct interaction with the dynein intermediate chain within the dynein microtubule motor complex (5) and by an indirect interaction with dynein via its association with a complex containing huntingtin-associated protein 1 (HAP1) and dynactin (6). In the presence of mutant Htt, dynein function is compromised, perturbing vesicle and organelle transport along microtubules.

In this issue of the JCI, Keryer and colleagues have linked the function of $\mathrm{Htt}$ in intracellular transport to ciliogenesis (7). As mutant Htt was found to cause hypermorphic ciliogenesis and ciliary dysfunction, it is possible that several symptoms of HD might be caused, at least in part, by ciliary dysfunction.

\section{Cilia and ciliopathies}

Primary cilia are single hair-like protrusions $1-5 \mu \mathrm{m}$ in length that are present on virtually all cells, including neurons and glia $(8,9)$. Primary cilia are nonmotile and have a microtubule skeleton consisting of nine microtubule pairs $(9+0$ axoneme), whereas motile secondary cilia have the same outer nine microtubule pairs, but include inner and outer dynein arms and a pair of central microtubules $(9+2$ axoneme) (Figure 1). Primary cilia in mammalian neurons are derived from a centriole within the centrosome and are located on the soma or proximal portion of the apical dendrite. They are thought to be involved 